and unaccompanied by any appreciable deformity. On the internal membrane of the cheek a transverse sulcus, with slightly elevated margins, could be felt, from which the saliva flowed into the mouth.

CAsE 2.-Sarah Mine, a country girl, applied to me in July, 1836, with a fistulous opening on the right cheek, which had been present since an abscess had formed, and been opened with the lancet. Caustics and compression had been employed by the medical man who had opened it, withont avail. The perpetual dribbling down of the saliva was giving rise to a train of evils. On introducing an Anel's probe at the ulcer it easily glided towards the parotid, though it would not go towards the orifice of the mouth, which I found to be obliterated, on passing the probe from the natural opening.

In this case I proceeded in the operation as with the previous patient. Herrecovery was, however, more speedy, being unaccompanied with the subsequent abscess.

CASE 3.-Richard White, at. 50, was under my care in Oct., 1837, having lacerated his cheek by a fall upon some stones. The wound extended into the buccinator and masseter muscles; its edges were carefully brought together, and over it a compress was placed, and the patient was cautioned against disturbing the application. The wound healed rapidly, and with the exception of a small fistula, through which there was a discharge of a clear liquid, especially while eating, which showed that the Stenonian duct had been wounded.

From the man's great objection to an operation, some months elapsed prior to its being commenced. During the interval several fruitless attempts were made to effect a cure.

In this case $I$ again converted the fistula into a recent wound, by the excision of its sides; then, with a small trocar, I perforated the cheek, from the wound, passing the instrument obliquely backwards. Having withdrawn the stilette through the canula, which remained in the perforation, 1 passed the end of a fine leaden wire. Then withdrawing the canula, I, in the same manner, made a second puncture, beginning, however, within the mouth, about three lines anterior to the former puncture, carrying the point of the instrument obliquely until it passed into the wound, near the place where the wire was inserted. The external end of the wire was passed through this opening into the mouth. Being thus bent somewhat in the form of the letter $v$, the ends of the wire were then twisted together, and the external wound was closed by a needle, and the twisted suture was employed. For the first three days there was some distention and pain, owing to the saliva not passing at first very readily by the side of the wire. On the fifth day the saliva passed freely into the mouth, and the swell- ing was nearly gone; the external wound had united, and the needle was then removed. Still the internal fistula was not so complete as to carry off all the saliva while the patient was cating.

The duct was distended into a kind of sac, producing during his mcals a small tumour, which was, however, easily emptied into the mouth, by a very slight external pressure. The leaden wire remained inside the cheek until the cure was complete.

80, Connaught Terrace,

Nov. 16, 1837.

\section{CASE OF \\ STRICTURE OF THE URETHRA CURED BY DIVISION.}

By Edward V. Mainwaring, Esq., Surgeon, Birmingham.

Mr. B-, a retired maltster, aged 55 , in easy circumstances, residing in this neighbourhood, consulted me on the 5th November, 1836 , in consequence of great difliculty in voiding his urine. He stated that he had never suffered from any serious complaint, with the exception of repeated attacks of syphilis and gonorrhoea during youth; but he had been subject to difficult micturition, with occasional discharge of mucus, for the previous fourteen years; that he had been under surgical care for the last three years, and that the treatment was commenced by the use of the catheter, caustic bougie, and stilette; that soon after their use he had a painful straining on attempting to relieve the bladder, with occasional prolapsus recti, and a constant involuntary oozing of urine night and day, which rendered the odour from his clothes so offensive, that he became an object of disgust, not only to himself, but to all around him. These instruments had been since frequently used, but without the slightest relief, and he stated that a full. sized catheter had been often passed its whole length, but he felt assured that it had never entered the bladder. His general health had, for some time, been declining; his appetite impaired; bowels confined, and he had becone much emaciated; the difficult micturition, urgent straining on attempting to make water, with occasional prolapsus recti, and the involuntary oozing of urine, have gradually increased during the three years previous to his consulting me. He then complained much of a bearing down about the rectum, and there was considerable pain and tenderness on pressure about the lower part of the bowels; no hemorrhoids; his countenance pale and haggard; pulse 87 , soft and regular; tongue thickly coated with a creamcoloured fur; skin soft and moist; but at night violent perspirations came on, which saturated the clothes; sleep much disturbed. 
On exumination I found a hard cartilaginous thickening of the urethra commencing just before the bulb, and extending an inch or more; the prostate gland was increased in size, but not painful to the touch. A fullsized soft bougie passed with ease down to the stricture, and I made some efforts to force it through, but did not succeed; a common-sized catheter was next tried, and by keeping its point steadily against the upper portion of the urethra, I insinuated it into the stricture, and by continued pressure, it passed into the bladder, and there immediately flowed forth three or four ounces of urine, dark-brown in colour, and highly offensive, depositing in a short time a considerable quantity of mucus, during the expulsion of urine. I distinctly felt the fluttering blows of the bladder, as described by Mr. Guthrie, and I desired my patient to lie down and turn into several positions. On his turning to the left side, more urine issued from the catheter, of the same offensive character; when the urine had ceased to flow, he complained of the catheter giving him great pain, and I withdrew it, recommended hin to lie in bed with the pelvis raised higher than the thorax, to take 3 iij of the decoction of pariera brava, four times a day; to use 40 drops of laudanum in a starch injection, when the pain and bearing down came on, moderate diet, and a grain and a half of opium at bedtime.

Nov. 6. Feels better; has had less oozing of urine during the night, and makes water easier. After several attempts $I$ introduced the catheter again, with similar results to those obtained yesterday. It was clear that my patient was unable to relieve the bladder effectually, without artificial means, for he had made every effort to empty it, just before my visit; the catheter was again withdrawn on account of the pain it gave. Continue medicine, \&c.

7. Same report as yesterday.

8. To-day he feels as if he could bear the catheter, and a gum-elastic one on an iron stilette was therefore introduced, and left in lis bladder. Continue treatment as before.

9. Has had much pain and irritation from the catheter, and has vomited several times during the night; the matter ejected is of a light verdigris colour. To have some effervescing draughts frequently, each containing one drop of hydrocyanic acid, and the opiate pill at bedtime; the catheter to remain.

10. The irritation from the catheter has produced such severe vomiting and prostration, that I am obliged (however reluctant) to withdraw it. To apply fomentations, and continue as yesterday.

11. Feels better; has passed a comfortable night; the oozing of urine has ceased, and $I$ determined to discontinue the use of the catheter, until all irritation had subsided. The draughts to be omitted; the decoction to be resumed as before.
14. The irritation having subsided. I tried the catheter again; it passed with ease its ful! length, but no urine escaped, my patient exclaiming at the same time that it was in the same passage as the medical gentleman who was his former attendant had always entered. This appeared to be the case; for after withdrawing the instrument a profuse bleeding took place, which continued several minutes; shivering and sickness supervened. These symptoms subsided in three hours, and I left him requesting that the same treatment might be continued as before.

18. To-day I made another trial of the catheter, but the same nisfortune attended this attempt, and in two hours after leaving the house, I was recalled by a message, stating that my patient was dying. 1 hurried back, and found him vomiting and retching violently; a cold clammy perspiration pervaded his whole frame; his pulse feeble and quick; his articulation scarcely audible. I immediately gave him some ammonia, camphor mixture, and laudanum, which relieved him considerably; he however complained of faintness and sickness the whole night, and I gave him repeatedly the effervescing draughts, containing one drop and a half of hydrocyanic acid in each, and twice a pill containing two grains of opium.

19. He is much rallied, but still very weak and low; urine deposits quite as much mucus as before, and the involuntary oozing has returned. To continue as yes. terday.

24. Much better, and I recommended him to have the stricture divided. This he refused, and hoped I should be able to make a passage without cutting. I explained the necessity for such an operation, but he still persisted in refusing, leaving me no alternative, but to recommend him to continue the use of the decoction as before, and half a grain of acetate of morphia at bedtime. This treatment he steadily adhered to with benefit, up to December 12th, when he had an attack of influenza, which debilitated him and increased his urinary complaints to a great degree, and at this time Dr. Evans was consulted. The treatment prescribed relieved him; and in ten days he was able to resume his usual pursuits; the decoction of pariera brava was again given with the addition of 30 drops of dilute nitric acid to each dose, and his general health attended to as before. He remained better until June; that is, he could make water in a fuller stream, his urine did not deposit so much mucus, the involuntary oozing was lessened, but still troublesome, and his strength and spirits were much rallied. In the beginning of June he caught cold and his urinary disease became much aggravated; he now had frequent desire to make water, great straining and bearing down 
about the anus and neck of the bladder; the stream of urine very small, with frequent interruptions from flakes of mucus plugging up the urethra; the urine alkaline, darkcoloured, and highly offensive. I again tried to relieve him by means of the catheter, \&c., but all my efforts to pass it info the bladder were fruitless, and I repeated my request to be allowed to divide the stricture, and to obtain a good passage into the bladder. After some delay he consented, and on the 13th of June he submitted to the operation, Mr. D. W. Crompton and Mr. Baker, a student of Mr. Ledsam's, kindly assisting. Having secured him on the table, as for lithotomy, 1 made an incision in the perineum down to the stricture, which I carefully divided a: $\mathrm{far}$ as the hardness existed. I now explured with the finger, and feeling satisfied that the uiseased parts were completely divided, I selected a small gum catheter, and was fortunate enough to fiud the other portion of the urethra, and to pass it into the bladder. I now thought if this catheter could be passed up the other portion of the urethra, the operation would be complete. For this purpose I selected a large-sized gum catheter, and passed it dnw'n the urethra, and drew the point back through the wound in the perineum; I then cut off the end, and also cut off the top of the small catheter that was in the bladder, screwed it into the open end of the large catheter", and gently drew it up the urethra; by these means the small catheter was introduced the whole length of the urethra, and having secured it there, I dressed the wound with a little oiled lint, and put my patient to bed. He bore his operation exceedingly well, and I left him under very favourable circumstances, recommending an anodyne draught at bedtime, if necessary, and an enema next morning. At the end of five days I withdrew the small catheter, and passed with ease a full-sized one, which remained in his bladder without causing the least uneasiness. I recommended him to use mjections into his bladder two or three times a day of warm water, occasionally changing it for decoction of marsh mallows, which afforded him much comfort; and he took, as medicine, the decoction with nitric acid as before. At the end of a fortnight the wound was quite healed, and he had so much improved in health that the catheter was withdrawn, and introduced once a day only. In the beginning of August my patient was capable of introducing the catheter himself, at any time he felt disposed; the mucous deposit had entirely ceased, and the bladder seemed to be gaining its natural capaciry. I had an interview with him last week. He cculd make water in a full stream; the involuntary oozing has never troubled him since the operation; the pain and bearing down about the rectum and bladder have also entirely ceased; bowels quite regular; appetite good; he has the appearance of robust health; and he stated that he never was better in health in his life.

\section{ASCITES TREATED BY ACUPUNC. TURE.}

To the Editor of THE LA NoET.

SIR :-I have read in last Saturday's No. of Tire Lancis, an account of a case of ascites treated by acupuncture. It reminded me of some cases which I treated by acupancture, about two years ago; and I should have been happy to have sent you the notes taken at the time conld I have laid my hands on them. I have also, in the Infirmary at this place, a very bad case of ascites, of fourteen months' standing, in a girl about nineteen years of age, which has resisted various remedies under one of the medical gentlemen resident here, tapping having been once performed, and in which I am endeavouring to give relief by acupuncture; but having only begun puncturing about eight days, I have no decided results to relate.

My general impression of acupuncturation in cases of abdominal dropsy, under my own experience, is that, while it does no harm in all cases not depending on an inflamed or tuberculated state of the peritoneum, it will prove an important auxiliary to the action of diuretic medicines, and may not unfrequently prevent a resort to tapping.

I should fear that the punctures recommended by Mr. King, will prove to be too numerous, - at least, I have never found it necessary to exceed three,-on alternate days, or thrice a week, as circumstances may allow of. The operation is attended neither with pain nor difficulty, a drop of the effused fluid, like a bead, following the exit of the needle, being the unequivocal sign that the peritoneum has been penetrated.

I do not know that there is any novelty in this operation, or mode of treatment in dropsy, for I think I can recollect that it has been recommended as far back as 1821 .

Now that the practice is made known in your widely circulating Journal, I trust it will be fairly tried by men enjoying extensive opportunities of making such professional experiments; I have little hope of this trifling operation, or any thing else, doing good, in the case now under my treatment; but if I should succeed I shall be happy to send you my memoranda. I remain, Sir, your most obedient,
Physician to General Infirmary Hertford, Nov. 20, 1837 .
J. J. Furnival. M. M., at Hertford.

